ESTUDOS REEP

\title{
O financiamento da educação na Rbep: temas dos últimos 15 anos*
}

Jacques Velloso

\section{Resumo}

Trata dos artigos sobre financiamento da educação publicados na Revista Brasileira de Estudos Pedagógicos (Rbep) durante os últimos 15 anos. Discute a agenda de estudos sobre financiamento da educação no plano internacional e busca situar os artigos publicados no âmbito desta agenda. Constatou que os sistemas públicos de ensino receberam grande atenção entre os artigos publicados, assim como ocorreu com o conjunto das esferas de governo: União, Estados e municípios. Entre os temas que dizem respeito a todos os três níveis de ensino e às três esferas de governo, destacou-se a vinculação constitucional de recursos para manutenção e desenvolvimento do ensino, mas questões referentes à equidade e à eficiência, bastante presentes naquela agenda, não foram bem contempladas nos artigos da Rbep.

Palavras-chave: Financiamento da educação; sistemas públicos de ensino; verbas para manutenção e desenvolvimento do ensino; despesas e receitas; equidade e eficiência.

* Partes do presente texto estão baseadas em Velloso (2001) 


\section{Abstract \\ The financing of education at Rbep: last 15 years' themes}

The text dealt with articles on education financing published in the Revista Brasileira de Estudos Pedagógicos (Rbep) during the past fifteen years. It discussed the agenda of studies on educational financing on an international level and attempted to place those articles within this agenda. It verified that the public systems of education received great attention among the articles published as well as the set of the three levels of government - the Union, the States and the Municipalities. Among topics that have to do with all levels of schooling and with the three levels of government, relevance was given to constitutionally defined resources for the maintenance and development of educational systems, but issues regarding efficiency and effectiveness, which are often included in that agenda, were not given the attention that they deserved in Rbep's articles.

Keywords: education financing; public educational systems; resources for the maintenance and development of educational systems; expenditures and revenues; equity and efficiency.

\section{Introdução}

Uma Introdução a um artigo usualmente situa o leitor no contexto em que se desenvolve o trabalho e, tomando-o pela mão, o conduz a uma resumida e prévia visão do texto, antecipando em breves palavras o que ele irá encontrar; ajuda-o a fazer o caminho que irá percorrer em sua leitura. Mas esta Introdução é algo diferente: é um preâmbulo a um texto que, como vários outros do número especial da Revista Brasileira de Estudos Pedagógicos (Rbep) comemorativo dos 75 anos do Instituto Nacional de Estudos e Pesquisas Educacionais Anísio Teixeira (Inep), dedica-se à discussão de artigos publicados sobre os temas mais recorrentes neste periódico nos últimos 15 anos. Assim, a presente Introdução pode ser mais simples e menor que as habituais.

O presente artigo trata dos trabalhos sobre financiamento da educação publicados na Rbep nos últimos três lustros. Além desta Introdução, o leitor encontrará outras três seções. Na seguinte apresenta-se um breve panorama do financiamento da educação no plano internacional, abordando suas origens, a posterior diversificação da agenda de pesquisas e os novos rumos que a agenda tomou. Na terceira trata-se dos trabalhos sobre financiamento da educação publicados na Rbep durante o período citado, discutem-se os recortes adotados pelos artigos e os temas transversais 
por eles abordados e contextualizam-se tópicos de trabalhos mais antigos; parte da discussão é situada no plano da literatura internacional. Uma nota final fecha o texto.

\section{Um breve panorama no plano internacional}

Os estudos sobre o financiamento da educação ganharam fôlego nos países cientificamente centrais com o surgimento de um novo campo há cerca de meio século: o da economia da educação; na literatura internacional, a consolidação das pesquisas sobre o financiamento ocorreu a partir daquela época. O texto de Benson (1970), um dos clássicos na área e cuja primeira edição foi lançada em 1961, é ilustrativo da concepção que dominou boa parte dos estudos conduzidos a partir de então e durante algumas décadas.

\section{A economia da educação e o temário do financiamento}

A Economia da Educação, disciplina que originalmente balizou os estudos sobre o financiamento do ensino, começou a ter identidade própria a partir dos trabalhos de Schultz e de Becker, na virada dos anos 50 do século passado, com artigos considerados como seminais por muitos economistas, porém suas obras mais conhecidas foram publicadas alguns anos depois (Becker, 1964; Schultz, 1963). Por vários anos o livro de Schultz teve maior impacto entre os não economistas, mas foi Becker quem trouxe mais densidade teórica à disciplina; ambos situavam-se na tradição teórica neoclássica. Com boa dose de simplificação, pode-se dizer que os economistas dessa vertente imaginavam a economia regida pela mão invisível de Adam Smith, tendendo ao equilíbrio - desde que o Estado não interviesse. Como se tal cenário fosse de fato observado, nele geralmente desenvolviam suas teorias e pesquisas empíricas.

O clássico texto de Benson, antes mencionado, situava-se na tendência dominante na economia da educação daquele tempo. No plano internacional, tanto Benson como alguns outros autores da mesma linhagem teórica pautaram boa parte - possivelmente a maioria - dos estudos sobre o financiamento da educação por mais de uma década. Benson, em suas próprias palavras, desejava examinar os problemas da educação pública que podem ser formulados em termos financeiros ou econômicos, explorando duas grandes questões. A primeira indagava como as escolas, operando como uma atividade pública descentralizada [nos Estados Unidos da América (EUA)], poderiam obter recursos suficientes para levar a cabo adequadamente suas tarefas. A segunda preocupava-se com a eficiência nos gastos, qualquer que fosse o montante de recursos que estivesse disponível para o financiamento das escolas. Outra ordem de preocupações dizia respeito à equalização de oportunidades educacionais (Benson, 1970, p. 3-4, 158). 
A proposta de estudos sobre financiamento da educação elaborada por Benson nos anos 60 visivelmente abrangia três perspectivas de análise. Uma, a da receita, isto é, a das fontes ou a da captação dos recursos; a proposta se perguntava então como e onde obter as verbas desejadas ou necessárias para determinados fins. Outra, a dos gastos ou a das despesas; nesta ótica destacava o tema da eficiência, que, na utilização dos recursos, sempre se fez presente na teoria e em estudos empíricos na área da economia em suas diversas vertentes teóricas. A terceira perspectiva era a da equidade; questões relativas a este tema, como as referentes à equalização de oportunidades educacionais, já faziam parte - na época, menor - da agenda do financiamento da educação nos EUA, país que, em larga medida, estabelecia a pauta das pesquisas na área. Na época o tema tinha relevo, consideradas as conhecidas diferenças de qualidade na oferta do ensino obrigatório - advindas em larga medida de desigualdades entre os montantes de recursos destinados às escolas de educação básica (nos EUA), financiadas sobretudo com verbas dos distritos nos quais se situam - e considerado o projeto de uma democracia liberal naquele país.

Havia ainda uma quarta perspectiva, menos visível na síntese acima esboçada. A proposta não pretendia apenas obter respostas que conduzissem a princípios teóricos genericamente aplicáveis; buscava ir mais além, obtendo diretrizes que pudessem ser adotadas por governos estaduais e prefeituras no financiamento da educação. Numa palavra, a proposta desejava que os estudos a serem conduzidos gerassem implicações para a gestão do ensino público. O financiamento da educação nos clássicos do século passado configurava-se como um campo que buscava avançar no plano conceitual, mas também procurava aplicações práticas no âmbito das políticas públicas.

Ao buscar respostas para as questões de sua agenda, o autor ora adotava a lógica da economia neoclássica, ora outra; entendia a economia de seu país como um sistema de preços ou como uma economia de mercado autorregulada. Em tal sistema, a justificativa para o financiamento público do ensino se baseava no princípio de que a educação trazia relevantes benefícios sociais, para além daqueles que eram apropriados privadamente por cada pessoa. Nessa lógica de análise, nem todos os benefícios que a educação gerava para a sociedade seriam adequadamente apropriados pelo dito sistema de preços - como os salários das pessoas; ${ }^{1}$ por exemplo, não refletiriam todos os benefícios sociais que a escolaridade traria para o conjunto do corpo social. Isso resultaria em ineficiências ou distorções na destinação de recursos para o ensino por parte da sociedade. Considerando que a educação obrigatória é uma condição da cidadania, justificava-se então a existência de redes públicas de educação básica mantidas pelo Estado.

\section{Diversificação da agenda e novos rumos}

Os modelos de análise do financiamento da educação sofreram substantiva diversificação ao longo dos anos, até por conta das fortes

\footnotetext{
${ }^{1}$ Na ótica neoclássica, o raciocínio subjacente é o de que, numa economia competitiva em equilíbrio, os salários seriam equivalentes à produtividade marginal do trabalhador, ou seja, à sua contribuição ao processo produtivo. Para uma tentativa de contraste entre tal abordagem e outra alternativa, veja-se, por exemplo, Velloso (1995).
} 
críticas que se fizeram à economia neoclássica. Na década de 90 do século passado, a agenda dos estudos sobre financiamento que antes se desenhara manteve suas preocupações com o nível dos recursos necessários, a fim de que um dado sistema de ensino pudesse adequadamente levar a cabo suas tarefas, embora tal questão nunca tivesse sido respondida adequadamente. A agenda manteve também suas indagações quanto à equidade e à eficiência na distribuição dos recursos.

Com o tempo, os enfoques inicialmente limitados do financiamento da educação gradualmente cederam lugar a perspectivas mais amplas. O tratamento da equidade no ensino superior, por exemplo, passou a acolher pelo menos duas abordagens: uma, a adotada nos Estados Unidos, na qual as principais formas de apoio financeiro para o ensino superior consistem num sistema de dotações e de empréstimos concedidos diretamente aos estudantes, e cujo montante está relacionado (inversamente) à renda familiar; a outra, adotada na Europa e na maioria das economias emergentes e dos países em desenvolvimento, na qual o governo central arca com a maioria dos custos da educação pós-secundária, incluída a manutenção dos estudantes, sendo as verbas destinadas às instituições (Benson, 1995, p. 411).

O desenvolvimento da pesquisa na área viu surgir um subcampo novo e específico: o do financiamento escolar, voltado para o ensino fundamental e médio e, por vezes, para a educação infantil. Valendo-se amplamente de contribuições de outras áreas, como a política da educação e a legislação do ensino, utilizando princípios da economia da educação e das finanças públicas e relacionado à administração da educação, conforme o definia um autor já clássico nesse campo (Levin, 1995, p. 412), o financiamento escolar gradualmente ganhou uma boa dose de autonomia, deixando de ser totalmente cativo da Economia da Educação, disciplina que o impulsionou por um bom tempo. Junto com ele, rumo análogo tomou o financiamento da educação, campo que incluía o anterior e havia tido impulso análogo.

Nessas trajetórias, a do campo mais abrangente e a do campo mais específico, a questão do custo-aluno ganhou destaque nas últimas duas décadas do século passado. Se a questão dos custos por aluno sempre esteve presente nos estudos do financiamento do ensino, em virtude de sua origem na economia da educação, na qual o tema dos custos sempre foi matéria do dia a dia, mais razão haveria para seu destaque em tempos de declínio das receitas públicas.

Naquelas duas décadas, e sobretudo nos anos 80, a redução na taxa de crescimento econômico da maioria das economias do cenário mundial e a queda da renda per capita que assolou muitas nações emergentes e em desenvolvimento, contribuíram para diversificar o foco dos estudos sobre financiamento do ensino. Naquela década, a América Latina, então o continente mais endividado do mundo, sofreu fortes pressões de agências financeiras internacionais e de países emprestadores para reduzir os gastos públicos, privatizar empresas públicas e, nas atividades custeadas pelo Estado, encontrar novas fontes de recursos, como mostraram Carnoy e Torres (1992). Estudos diversos indicaram ainda que 
as políticas de reestruturação (ou do dito ajuste) levadas a cabo nesses países geralmente resultaram em efetiva redução nos gastos públicos no ensino, com reflexos danosos sobre os salários dos professores e sobre a qualidade da educação.

Na época, agências financeiras internacionais, como o Banco Mundial (Bird) e, mais tarde, também o Banco Interamericano de Desenvolvimento (BID), passaram a ter destacados papéis na formulação da agenda dos estudos e, em certa medida, também das políticas do financiamento. O Bird tornou-se um vigoroso produtor de pesquisas na área; ademais, as cláusulas de condicionalidade estipuladas em seus empréstimos a países em desenvolvimento frequentemente conduziam a políticas muito diversas das que até então vinham sendo adotadas por aquelas nações. ${ }^{2}$ Tanto os estudos realizados pelo Bird como as políticas acordadas nos empréstimos direcionavam-se para a chamada "recuperação de custos" - eufemismo para a cobrança de mensalidades em instituições públicas de ensino - e para medidas análogas, isto é, para a privatização dos serviços educacionais, como bem ilustram as propostas apresentadas num trabalho oficioso elaborado por Psacharopoulos et al. (1987) e preparado para o Bird. Nos estudos, invariavelmente conduzidos sob a ótica da economia neoclássica - vez por outra com algumas qualificações -, tiveram destaque temas como equidade, custos da educação, bolsas de estudo e empréstimos a estudantes.

A agenda do Banco Mundial (e do BID) para o financiamento da educação veio a ser parcial e provisoriamente confrontada com uma proposta da Organização das Nações Unidas para a Educação, a Ciência e a Cultura (Unesco) sobre o mesmo tema, divulgada na segunda metade dos anos 90 do século passado, especialmente no que dizia respeito à educação superior, nível de ensino no qual eram maiores os contrastes entre ambas (Velloso, 2000). O tempo e o jogo político das nações, entretanto, iriam se encarregar de produzir um lamentável aumento de coincidência entre a proposta da Unesco e as dos outros dois organismos internacionais.

O período também testemunhou o surgimento de debates sobre a conexão entre avaliação e financiamento. Na sua origem, tendo fortes - mas não exclusivas - vinculações a políticas de governos neoliberais (ou neoconservadores, como denominados em muitos países do hemisfério norte) e a recomendações de agências financeiras internacionais, tomou corpo o debate sobre as relações entre resultados de avaliações de instituições de ensino e a alocação de recursos públicos, com ênfase na educação superior, mas não apenas neste nível. O tópico da avaliação conectada à alocação de recursos públicos, assim como o tema da privatização, seguramente constituíram-se nas duas principais inovações da agenda dos estudos e das políticas de financiamento da educação nas duas últimas décadas anteriores à virada do século.

Mantendo sua influência sobre a agenda de estudos do financiamento do ensino, o Banco Mundial, em 2005, divulgou documento sobre suas recomendações para o setor educacional e, em 2011, lançou texto que pretendia atualizar suas propostas com vista à próxima década, 2020.
${ }^{2}$ Para uma análise do caso brasileiro, veja-se, por exemplo, Fonseca (1998) 
Um estudo sobre este texto mais recente indica que, do ponto de vista do financiamento da educação, houve alterações em relação às políticas antes recomendadas pelo Banco, mas elas foram pequenas (Verger; Bonal, 2011). Na ótica do financiamento, a principal mudança ocorreu no critério para alocar gastos públicos em educação: antes, baseado nas taxas de retorno (monetário) ao investimento educacional; no documento mais recente, voltado para a construção de "economias do conhecimento", na qual os gastos dos governos com as universidades teriam papel maior. Apesar de tal mudança, e como bem analisaram Verger e Bonal do ponto de vista do financiamento da educação, a nova proposta, em seu âmago, deu continuidade programática às anteriores, mantendo o papel-chave antes atribuído ao setor privado - inclusive às instituições com fins lucrativos - e continuando com a pretendida relevância dos "mercados educacionais", nos quais os vouchers (adiante discutidos) assumiriam um novo protagonismo.

Durante a última década do século passado e, mais tarde, enquanto o Banco Mundial buscava modernizar suas antigas propostas, delineava-se uma importante inovação quanto às abordagens do financiamento. Com raízes no hemisfério norte, mas com desenvolvimento sobretudo local, particularmente na América Latina, e já plenamente consolidada na virada do século, a economia política do financiamento da educação colocou no centro das análises as políticas do Estado e suas finalidades e resultados. Utilizou como ponto de partida as responsabilidades do Estado para com o financiamento da educação pública, decorrentes do princípio do direito à educação; adotou um destacado critério de análise de resultados, a boa qualidade do ensino que deveria estar disponível para todos. Foi bem-vinda por todos os títulos, embora não contasse com a alavanca dos recursos que estavam à mão de vertentes tradicionais.

Na nova abordagem da economia política do financiamento, a atuação do Estado na educação - em especial no ensino público - passou a ser tema privilegiado. Além disso, as análises do financiamento passaram a se situar na discussão de um projeto para uma sociedade democrática.

Durante a primeira década do novo século, o cenário da agenda do financiamento no plano internacional já não se configurava exatamente como o do final do século anterior. Várias das tendências pregressas permaneciam, mas agora sofriam a influência de um pretendido aggiornamento da agenda do Banco Mundial - que, como sempre, caminhava no sentido de privilegiar o setor privado e de privatizar o ensino público -, acomodavam a minoritária participação da economia política do financiamento e continuavam valorizando a avaliação conectada à destinação de recursos.

A novidade do século 21 foi o surgimento de estudos sobre o financiamento de dois tipos de experiências de privatização do ensino, iniciadas na década anterior nos Estados Unidos da América (EUA): a criação do vale-educação (vouchers) e de um novo tipo de instituição na educação básica, que não seria pública nem privada - as escolas por contrato com organizações não governamentais ou mesmo com entidades privadas (charter schools). 
O vale-educação teve sua origem nas propostas de Milton Friedman, que vieram à luz há exatamente meio século, quando da publicação de um de seus seu livros em 1962 (e traduzido no Brasil bem depois), uma profissão de fé nas virtudes do capitalismo como instrumento da liberdade humana (Friedman, 1977). O vale-educação, como seu próprio nome sugere, se assemelha, digamos, a um vale-refeição ou vale-transporte. Com ele, que é fornecido pelo poder público a famílias com crianças e jovens em idade escolar, os pais poderiam pagar matrícula e anuidade para seus filhos em escolas privadas (Levin, 2002). Foi implantado em várias cidades de diversos Estados daquele país, assim como foram as escolas por contrato (não necessariamente nas mesmas cidades e Estados).

Estas, as escolas por contrato, têm seus custos cobertos pelo poder público, mas não se submetem às mesmas regras que regem a contratação de professores e a gestão das escolas públicas. Criadas com base na presunção de que a gestão privada (ou não estatal) das escolas seria mais eficiente que a gestão pública, a evidência disponível em estudos conduzidos em mais de uma dúzia de sistemas escolares norte-americanos não sustentou tal suposição; ao contrário, indicou que a média do desempenho dos alunos das escolas por contrato em geral é inferior à media do desempenho dos estudantes das escolas públicas (Carnoy et al., 2005). Além disso, recente estudo naquele país, com dados para 40 Estados, constatou que a matrícula das escolas-charter apresentava "frações desproporcionalmente elevadas de estudantes negros quando comparadas a outras escolas públicas" e, de modo análogo, mas no sentido inverso, "frações extremamente baixas de estudantes brancos" (Frankenberg; Siegel-Hawley; Wang, 2011, p. 18-19), assim contribuindo para isolar os alunos conforme sua raça e classe social.

\section{Estudos sobre o financiamento da educação na Rbep}

Uma vez esboçada, em largos traços, a evolução do temário dos estudos do financiamento da educação no panorama internacional, interessa agora indagar como se configuram os artigos publicados na Rbep no período analisado.

Convém inicialmente identificar o perfil profissional dos autores dos 13 textos sobre financiamento da educação publicados na Revista no período estudado. Constatou-se que a grande maioria é de docentes da educação superior (nove autores); um artigo é de docente em coautoria com mestrandos, dois trabalhos são de doutorandos e um é de profissional não docente. A alta concentração de trabalhos de autoria de docentes da educação superior não causa estranheza, pois o prestígio de que desfruta a Revista, refletido em sua elevada classificação no Qualis de periódicos da área da educação, significa que é intensa a competição na submissão de trabalhos para eventual publicação; assim, os submetidos por pesquisadores em formação, que ainda não concluíram seu doutorado, têm chances bem menores de aceitação. De outra parte, a não exclusividade de artigos 
de docentes do ensino superior também é positiva, sugerindo que bons textos de doutorandos ou de profissionais da área têm acesso à Revista.

Outro aspecto de interesse diz respeito à conexão dos artigos com teses e dissertações. Um dos trabalhos está baseado em dissertação de mestrado, conforme explicita seu autor. Nos dois trabalhos de autoria de doutorandos não há indicação específica de que estejam relacionados a suas teses, mas, a julgar pela experiência brasileira da pós-graduação em Educação, é provável que a origem dos artigos resida em suas pesquisas de doutorado.

Prosseguindo com a caracterização dos trabalhos publicados no período, discutem-se os tipos de recorte dos objetos de estudo e, depois, os temas transversais que os marcaram. Na última parte contextualizam-se temas de artigos publicados há mais de uma década. A identificação dos recortes e temas transversais naturalmente dependeu do olhar do autor do presente trabalho e pretendeu, sempre que cabível, situá-los na agenda de pesquisas do financiamento no plano internacional.

No presente texto, a expressão "recortes do estudo" refere-se aos níveis de ensino e às esferas de governo que demarcaram os objetos de estudo nos artigos da Rbep. A expressão "temas transversais" diz respeito a assuntos, questões ou problemas que atravessam todos os níveis de ensino ou todas as esferas de governo. Na identificação dos recortes e dos temas transversais consideraram-se, em cada artigo, os principais focos da análise.

\section{Recortes}

Nos 13 artigos examinados, em seis deles - quase a metade - o foco principal da análise ora esteve voltado para o sistema de ensino público como um todo, dispensando qualquer recorte por nível educacional, ora para o conjunto dos níveis de ensino, tratando de cada um deles mas sem recortar o objeto de estudo em um nível específico (Almeida, 2001; Castro, 1998a; Davies, 2008; Jesus, 2007; Pinto et al., 2001; Sena, 2002). Nos demais trabalhos foram efetuados recortes por nível de ensino. O recorte de maior frequência foi o da educação básica - compreendendo desde a educação infantil até o ensino médio -, com três artigos publicados (Castro, 1998b; Davies, 1999, 2008; Parente, 2006). Por fim vieram os recortes por níveis de ensino específicos, com um texto cada um: educação infantil; instrução elementar (no Império); ensino médio (respectivamente, Carnielli, 2000; Gomes et al., 2010; Merchede, 1998). Não se registrou um único estudo especificamente sobre o financiamento da educação superior, uma lacuna importante.

De modo análogo ao que ocorreu com os níveis de ensino, porém com intensidade ainda maior, predominou a ausência de recortes por esfera de governo. Oito dos 13 artigos examinados - bem mais da metade tratou de questões do financiamento no conjunto das esferas de governo (Almeida, 2001; Castro, 1998a, 1998b; Davies, 2008; Jesus, 2007; Parente, 
2006; Pinto et al., 2001; Sena, 2002) - União, Estados e municípios - ou, quando discutia o financiamento numa delas, fazia o mesmo com respeito às outras duas. Em seguida vieram os trabalhos que enfocaram questões do financiamento no plano das unidades federadas, mas não na esfera estadual propriamente dita, pois dois deles se referiam tanto a escolas públicas como a escolas particulares selecionadas no Distrito Federal (Gomes et al., 2010; Merchede, 1998), e um tratava de recursos públicos propriamente na esfera estadual (Davies, 1999). Um trabalho tratou das esferas estadual e municipal (Davies, 2007), um único artigo incluiu a esfera federal (governo central) e os Estados (províncias, ao tempo do Império) (Carnielli, 2000) e nenhum se dedicou exclusivamente à União ou aos municípios.

No cenário internacional, o principal objeto de análise nos estudos conduzidos têm sido os recursos públicos, sem que isso indique necessariamente uma preferência dos pesquisadores pelo setor público; antes, isso decorre do fato de que, na educação básica, este setor comanda fatia muito maior de recursos para o ensino que o setor privado; no nível superior, exceto em países onde o ensino privado é dominante e movimenta um largo montante de recursos, o setor público também detém a maior fatia das verbas aplicadas. Ademais, dados sobre as receitas e os gastos públicos aplicados na educação devem estar ao alcance do público e dos pesquisadores, mas não do setor privado. O sucesso parcial da ingente insistência da proposta - e do poder dos recursos para empréstimos - de agências como o Banco Mundial, inserindo na agenda do financiamento estudos sobre a educação privada, não logrou alterar substantivamente o panorama. A única mudança digna de nota ocorreu no cenário norte-americano, no qual, desde a década passada, alguns estudos sobre financiamento se voltaram para temas como o vale-educação e as escolas por contrato; desses temas são ilustrativos os já mencionados estudos de Levin (2002), de Carnoy et al. (2005) e de Frankenberg, Siegel-Hawley e Wang (2011).

As pesquisas sobre financiamento publicadas na Rbep nos últimos três lustros em geral não se mostraram particularmente sensíveis àquela agenda de agências internacionais, mantendo as verbas públicas como seu objeto de análise quase exclusivo. Temas referentes a recursos privados foram abordados em apenas dois estudos; um deles analisava duas escolas de educação infantil, e o outro, duas escolas de ensino médio no Distrito Federal (Merchede, 1998; Gomes et al., 2010, respectivamente).

Nesse cenário, em boa parte - quase metade - das pesquisas publicadas na Rbep e que tinham o setor público como objeto de estudo, a responsabilidade do Estado pelo ensino público e a necessidade de sua valorização foi usualmente tomada como dado do problema examinado e não como uma questão a ser discutida. Esse tipo de perspectiva, ora adotada explicitamente pelos autores, ora subjacente ao texto, faz parte do olhar daquela economia política do financiamento antes aludida.

Em pesquisas sobre financiamento da educação, o ângulo de exame dos recursos pode ser o das receitas - vale dizer o das fontes ou da 
captação - ou o das despesas - vale dizer o dos gastos ou da aplicação -, ou, ainda, o de ambas as perspectivas. A ótica das despesas sempre foi largamente dominante no plano internacional, porém, a partir da última década do século passado, sem perder preeminência, cedeu algum espaço a estudos sobre novas fontes de recursos - em virtude da crise fiscal, que teve seu maior impacto nos anos 80 , e, em parte, também como reflexo do progressivo destaque obtido pela agenda das agências internacionais de financiamento, em tempos de crescente projeção de políticas sociais lastreadas em ideias neoliberais.

Entre os trabalhos publicados na Rbep, a grande maioria enfatizou a ótica das despesas (ou dos gastos) ou discutiu o financiamento exclusivamente nessa perspectiva. Sete dos 13 artigos trataram de gastos públicos em educação, em seu sentido estrito, isto é, discutiram dados sobre despesas públicas no setor educacional. Incluindo custos públicos e privados da educação na categoria das despesas, como de fato merecem ser incluídos, chega-se a nove trabalhos. Um dos artigos restantes abordou o formato da assistência financeira do Fundo Nacional do Desenvolvimento da Educação (FNDE) do Ministério da Educação a programas e projetos educacionais de governos estaduais e municipais, e, embora não discutisse níveis de gastos, seu foco no formato da assistência financeira permite classificá-lo como um estudo do lado da despesa. Dos três artigos que não tiveram seu principal foco em questões do lado dos gastos, dois trataram tanto de despesas quanto de receitas e um abordou questões do financiamento, sobretudo pelo lado da receita.

\section{Temas transversais}

No cenário internacional dos estudos sobre financiamento da educação, duas questões transversais em geral têm relevo: a da equidade e a da eficiência. No conjunto dos estudos veiculados na Rbep, esses dois temas transversais não tiveram presença muito marcante. Foram identificados três artigos que trataram de aspectos do tema da equidade como dimensões centrais do estudo, geralmente pela ótica das desigualdades ou disparidades regionais, e apenas um que abordou aspectos do tema da eficiência.

No primeiro grupo de trabalhos, referente a aspectos do tema equidade, o artigo de Castro (1998b), que tratou do gasto público em educação básica, discutiu as disparidades regionais, estaduais e municipais quanto à educação de 0 a 6 anos, ao ensino fundamental e ao ensino médio. Seus dados de natureza macro (referentes a 1995), agregados nos planos regional, estadual e municipal, revelaram que a despesa média por aluno no Sudeste era o triplo da despesa análoga no Norte e no Nordeste; de modo semelhante e no mesmo nível de ensino, o gasto médio por aluno nos Estados mais ricos e nos mais pobres diferia aproximadamente pela mesma ordem de grandeza. Redigido apenas pouco tempo depois que o Fundo de Manutenção e Desenvolvimento do Ensino Fundamental 
e de Valorização do Magistério (Fundef) havia começado a funcionar, e ainda sem informações consolidadas sobre seus efeitos, o autor manifestava a esperança de que o Fundo viesse a contribuir para a redução das disparidades constatadas no ensino fundamental.

Cerca de dez anos mais tarde, aspectos do tema da equidade voltavam às páginas da Revista como um dos focos centrais da análise de Davies (2008), que também se valeu de dados de natureza macro. Seu trabalho versou sobre fragilidades e incoerências do salário-educação, sobretudo tendo em vista seu uso no Fundo de Manutenção e Desenvolvimento da Educação Básica e de Valorização dos Profissionais da Educação (Fundeb) e, nesse contexto, discutiu desigualdades tributárias. O autor mostrou que uma fragilidade da nova sistemática do salário-educação era a de não ter corrigido as desigualdades tributárias entre regiões, estados e municípios, uma vez que os 60\% [das novas] cotas estaduais/municipais são devolvidos às unidades federadas onde foram arrecadados, beneficiando assim aquelas que têm economia formal (carteira assinada) relativamente mais desenvolvida (Davies, 2008, p. 450-451). Uma das consequências disso, para além da permanência das desigualdades tributárias, é a de que as diferenças nos valores do salário-educação por matrícula na educação básica, entre os Estados, em vez de diminuírem, como é o proclamado propósito do Fundeb, aumentaram vigorosamente. Os dados do autor permitem estimar que esse valor, na média para o Distrito Federal e São Paulo, é 16 vezes maior que a média para Maranhão e Piauí.

O terceiro trabalho do primeiro grupo, publicado em 2010, tratou do tema da desigualdade social associada ao reforço escolar e a seus gastos, numa pesquisa exploratória em duas escolas de ensino médio em Brasília, uma pública e outra particular. Ao contrário dos dois textos anteriores, esse artigo se valeu de microdados referentes a alunos dessas duas escolas e às suas famílias. O estudo mostrou que as despesas anuais com reforço escolar dos alunos da escola pública alcançou montante equivalente ao estimado pelo Fundeb para o aluno do ensino médio público urbano do Distrito Federal. Na escola particular, os gastos anuais dos estudantes atingiram quase o triplo do referido montante. Nas palavras de Gomes et al. (2010, p. 65), a baixa qualidade e o fracasso escolar, que remetem às aulas de reforço e respectivo material didático, têm efeitos tão mais perversos quanto menor é a renda familiar.

Um único trabalho abordou questões referentes à eficiência pelo lado das despesas; nas implicações dos resultados obtidos, tratou ainda aspectos da equidade. Valendo-se também de microdados como o trabalho de Gomes et al., o de Merchede (1998) examinou os custos da educação infantil em duas instituições do Distrito Federal. Na primeira, constatou a existência de capacidade ociosa, pois, conforme a direção do estabelecimento, este poderia atender ao triplo do contingente de crianças que o frequentavam, o que tinha reflexos negativos sobre os custos fixos. Ademais, quando foram comparados os respectivos custos com as mensalidades cobradas por instituições particulares, o autor verificou que havia ineficiência no emprego dos recursos. Na segunda instituição, que oferecia 
serviços mais modestos, conforme o autor, o desempenho mostrou-se de certa forma mais eficiente, considerada a relação entre custo e mensalidades nos estabelecimentos privados, o que o levou a concluir que esta, atendendo a famílias de baixa renda e sendo gratuita, oferecia maior contribuição para a equidade social do que a primeira.

Nos artigos publicados na Rbep sobressaiu outro tema transversal, o da vinculação constitucional de recursos para manutenção e desenvolvimento do ensino (MDE), que diz respeito às três esferas de governo e a todos os níveis educacionais. Este é um tema da maior relevância e tipicamente nacional, pois tal vinculação não costuma ser a norma em países cientificamente centrais.

Sob diversas perspectivas, o tema foi o foco central de quatro dos estudos publicados - quase $1 / 3$ do total -, incluindo um artigo que abordou os debates antes da e durante a Assembleia Constituinte de 1933/1934 e o papel dos Pioneiros da Educação Nova em torno da ideia da "manutenção e desenvolvimento dos sistemas educativos" (Jesus, 2007), conceito e nomenclatura adotados na Constituição Federal de 1934. Apesar de reveses sofridos em décadas posteriores, em tempos de autoritarismo, a vinculação iniciou seu pleno reingresso na Constituição Federal com a Emenda Constitucional no 24/83, a chamada Emenda Calmon. Incorporada na Carta Magna de 1988, a vinculação veio a integrar um quadro normativo amplo, que, além dos dispositivos da Constituição Federal, incluiu diplomas infraconstitucionais, como a Lei de Diretrizes e Bases da Educação Nacional (LDB), de 1996, além dos ordenamentos contidos nas constituições estaduais, nas leis orgânicas dos municípios e em normas correlatas.

Outro dos quatro artigos referidos, o trabalho de Sena (2002), traçou o percurso histórico da vinculação desde a Emenda Calmon; revelou que a União vinha cumprindo o mandamento constitucional, aplicando em MDE o devido percentual mínimo de impostos, ao contrário do que ocorrera anos antes, como mostrara Velloso (1990). Ecoando preocupações de pesquisadores na área, como as de Pinto et al. (2001), tratou da redução da base de cálculo dos recursos vinculados da União em virtude de cortes determinados pelo Fundo de Estabilização Fiscal (FEF), mais tarde sucedido pela Desvinculação de Receitas da União (DRU), sempre entendendo que a vinculação de recursos para a educação é uma decorrência lógica do princípio de que esta é um direito do cidadão e responsabilidade do Estado (Sena, 2002, p. 17). Com efeito, a vinculação de recursos para a MDE tem provido estabilidade de financiamento do ensino bem maior do que antes de sua existência, contribuindo ao longo dos anos para aumentar as chances de oferta de uma educação pública de boa qualidade para todos, exigência da cidadania.

Os outros dois artigos cujo foco principal foi a MDE tiveram a autoria de Davies $(1999,2007)$. Em seu trabalho mais antigo, à vista de graves falhas técnicas nos pareceres do Tribunal de Contas do Estado do Rio de Janeiro quanto às aplicações em MDE, num período de aproximadamente dez anos, Davies arguiu a necessidade de um maior controle social 
sobre tais gastos. Ao final de sua análise, apontou para a relevância da comparação entre receitas e despesas em MDE em estudos futuros, o que permitirá detectar irregularidades na aplicação das verbas. De fato, com tal comparação o autor identificou irregularidades nas contas de várias prefeituras do Estado do Rio de Janeiro. Em seu trabalho mais recente, e que teve como objeto de estudo as aplicações em MDE no (antigo) Estado de Mato Grosso, Davies verificou que o Tribunal de Contas aceitou o demonstrativo contábil do governo estadual, que incluiu, no percentual mínimo de despesas com a manutenção e desenvolvimento do ensino, gastos que não podiam ser assim contabilizados, pois não eram oriundos de impostos - como aplicações efetuadas com recursos do salário-educação, que é uma contribuição social. Constatou ainda uma aberração conceitual em alguns pareceres do mesmo tribunal: nestes, considerou que o imposto de renda pago pelos servidores estaduais e municipais não deveria ser considerado como imposto para fins do cálculo dos recursos vinculados à MDE.

\section{Contextualizando artigos}

Há algumas décadas, os trabalhos sobre financiamento da educação no País frequentemente refletiam as dificuldades de acesso a informações e as limitações existentes nos parcos dados então disponíveis sobre sistemas de ensino, particularmente no plano nacional. Na década de 80, o livro de José Carlos de Araújo Melchior sobre o financiamento da educação brasileira (Melchior, 1987), por exemplo, que naquele tempo era a única obra de envergadura disponível sobre o tema, muita vez lançava mão de dados divulgados vários anos antes da redação do texto, não porque fossem importantes para a construção de séries históricas, mas porque eram os únicos disponíveis. Pesquisar sobre o financiamento da educação, naquela época, consistia num verdadeiro garimpo de informações.

No ano seguinte ao da publicação daquela obra de Melchior, o autor do presente texto era convidado, como especialista, para prestar depoimento a uma Comissão Parlamentar de Inquérito (CPI) que havia sido instituída em 1988 na Câmara dos Deputados para apurar o cumprimento da Emenda Constitucional n 24/83, conhecida como Emenda Calmon, segundo a qual a União deveria aplicar pelo menos 13\% de sua receita de impostos para MDE. Apesar dos esforços envidados pelo autor, e das cartas de recomendação emitidas em seu favor pela referida comissão, não foi possível conseguir informações sobre a receita de impostos da União, embora tivessem sido obtidos dados minuciosos e suficientes quanto aos vários tipos de despesas em educação, permitindo identificar aproximadamente quais se enquadrariam no conceito de MDE (Velloso, 1990). A falta de informações sobre impostos foi superada, inesperadamente, quando um representante de órgão de governo, ao apresentar seu depoimento à CPI, enfim cientificou-a quanto à receita de impostos da União sobre a qual deveria incidir a vinculação dos 13\% para manutenção e desenvolvimento do ensino. 
É nesse contexto de algumas décadas atrás, das referidas dificuldades de obtenção de informações sobre o financiamento do ensino e das mencionadas limitações da magra disponibilidade de macrodados no plano nacional, que se deve adequadamente situar dois textos publicados na Rbep, um no final dos anos 90 e outro no início da década passada.

Um artigo de Jorge Abrahão de Castro, veiculado na Revista em 1998, utilizando informações sobre diversos aspectos do financiamento da educação no País, é bem ilustrativo de seu tempo. Seu breve texto sobre federalismo e educação, pleno de tabelas e gráficos com dados até então desconhecidos, sistematizados no âmbito do Instituto de Pesquisa Econômica Aplicada (Ipea), foi incluído na seção Estatística e não na seção Estudos da Rbep (ou noutra, análoga). Ele revelou como as disposições legais sobre a repartição de responsabilidades quanto ao financiamento da educação se refletiam no gasto público na área em 1995, nas três esferas de governo, e mostrou que a educação era um componente da maior importância nos gastos sociais, particularmente nas esferas estadual e municipal, constituindo-se assim num dos pilares da proteção social brasileira (Castro, 1998a, p. 99). Sua discussão indicou ainda que as transferências negociadas aos Estados e municípios tinham pouco peso nas despesas, situando-se num reduzido espaço de negociações políticas das verbas.

O trabalho de Almeida (2001), veiculado três anos depois do artigo de Castro, também é reflexo dos tempos de parcas e imprecisas informações sobre receitas e despesas públicas em educação. Tal como o texto de Castro, foi igualmente situado na seção Estatística da Rbep, na qual ocupou 61 páginas, sendo que mais de 3/4 delas continham apenas tabelas, certamente destinadas a consultas de especialistas que buscassem vencer a barreira da escassez de dados sobre o financiamento do ensino no País.

Versando sobre os gastos com educação entre 1994 e 1999, o trabalho apresentou variadas e minuciosas séries históricas da despesa por aluno, por nível de ensino, por Estado e por região; também por dependência administrativa, nível de ensino e por Estado, entre outras desagregações. O autor mostrou que havia ocorrido um notável crescimento dos gastos com o ensino fundamental, principalmente na esfera municipal, já um reflexo do recém-criado Fundef; revelou ainda que os gastos públicos em educação no País correspondiam a 4,3\% do PIB, valor inferior aos 4,5\% da Argentina e bem menor que a média dos países da Organização para Cooperação e Desenvolvimento Econômico (OCDE), com 5,2\%.

Vale notar que o autor, ao tratar da origem de seus dados, informava que eles haviam sido obtidos "a partir de uma metodologia desenvolvida pelo Instituto de Pesquisa Econômica Aplicada (Ipea)" (Almeida, 2001, p. 137, passim). A referência do autor a uma "metodologia do Ipea", um conjunto de procedimentos para a obtenção e consolidação de dados comparáveis ao longo de um período - sobre receitas e despesas públicas na área social, inclusive na educação, é bem um testemunho típico de seu tempo nas pesquisas sobre financiamento da educação. Hoje, a dita "metodologia do Ipea", de grande relevância nos anos 90, desde então 
continuadamente aperfeiçoada e que continua gerando informações de qualidade, já nem chega a ser um lugar comum. Muitos dos dados analisados por Castro e por Almeida nos anos 90 hoje estão acessíveis mediante um simples clicar de botões virtuais na internet.

\section{Nota final}

Os artigos sobre o financiamento da educação publicados na Revista nos últimos 15 anos abrangeram um largo espectro de temas na área do financiamento do ensino. A Rbep se mostrou, assim, um periódico de consulta ou leitura indispensável nessa área. Nesses textos, os sistemas públicos de ensino, analisados principalmente pelo lado das despesas, sobressaíram entre todos os demais objetos de estudo. Além dessa tônica, os trabalhos também estiveram em consonância com outros tópicos da agenda de pesquisas do financiamento no plano internacional.

Verificou-se ainda que a maioria dos trabalhos havia discutido questões do financiamento considerando o conjunto das esferas de governo - União, Estados e municípios - e o conjunto dos níveis de ensino. Alguns trabalhos trataram de níveis de ensino específicos, mas o financiamento da educação superior revelou-se a grande lacuna entre os objetos de estudo escolhidos pelos autores.

Entre temas que dizem respeito a todos os níveis de ensino e a todas as esferas de governo, destacou-se a vinculação constitucional de verbas para manutenção e desenvolvimento do ensino, tópico com características tipicamente nacionais e que não se refere à agenda de pesquisas no plano internacional. Essa vinculação recebeu a devida atenção nos artigos publicados, sendo tratada sob diversos aspectos.

Temas relativos à eficiência e à equidade, que igualmente dizem respeito a todos os níveis de ensino e a todas as esferas de governo, não foram bem contemplados nos artigos da Rbep, comparativamente à agenda internacional de pesquisas na área. Considere-se que a eficiência na aplicação das verbas públicas é um imperativo de ordem política e ética, pois recursos públicos pertencem a toda a população. Considere-se ainda que questões de equidade, situadas no plano da justiça social, requerem indispensável discussão na permanente construção de um renovado projeto de democracia para o País.

\section{Referências bibliográficas}

ALMEIDA, I. C. Gastos com educação no período de 1994 a 1999. Revista Brasileira de Estudos Pedagógicos, Brasília, v. 82, n. 200/201/202, p. 137-198, jan./dez. 2001.

BECKER, G. Human capital: a theoretical and empirical analysis, with special reference to education. New York: Columbia University Press, 1964. 
BELFIELD, C.; LEVIN, H. Education privatization: causes, consequences and planning implications. Paris: IIEP/Unesco, 2002.

BENSON, C. The economics of public education. 2. ed. Boston: Houghton Mifflin, 1970.

Educational financing. In: CARNOY, M. (Org.). International encyclopedia of economics of education. 2. ed. New York: Pergamon Press/Elsevier Science, 1995. p. 408-412.

CARNIELLI, B. L. O dispêndio com a instrução elementar no Império. Revista Brasileira de Estudos Pedagógicos, Brasília, v. 81, n. 197, p. 26-39, jan./abr. 2000.

CARNOY, M.; TORRES, C. Structural change and structural adjustment: a case study of Costa Rica. Paris: Bureau for the Coordination of Operational Activities, Unesco, 1992.

CARNOY, M. et al. The charter school dust-up: examining the evidence on enrollment and achievement. Washington, D.C.; New York: Economic Policy Institute, Teachers College Press, 2005.

CASTRO, J. A. Federalismo e gasto público com educação no Brasil. Revista Brasileira de Estudos Pedagógicos, Brasília, v. 79, n. 192, p. 92-100, maio/ago. 1998a.

. Gasto público com a educação básica. Revista Brasileira de Estudos Pedagógicos, Brasília, v. 79, n. 193, p. 135-147, set./dez. 1998b.

DAVIES, N. Tribunal de Contas: faz as contas ou faz-de-conta na avaliação dos gastos governamentais com educação? Revista Brasileira de Estudos Pedagógicos, Brasília, v. 80, n. 194, p. 19-27, jan./abr. 1999.

. Aplicação dos recursos vinculados à educação: as verificações do Tribunal de Contas de Mato Grosso. Revista Brasileira de Estudos Pedagógicos, Brasília, v. 88, n. 219, p. 345-362, maio/ago. 2007. . O salário-educação: fragilidades e incoerências. Revista Brasileira de Estudos Pedagógicos, Brasília, v. 89, n. 223, p. 445-454, set./dez. 2008.

FONSECA, M. O Banco Mundial como referência para a justiça social no Terceiro Mundo: evidências do caso brasileiro. Revista da Faculdade de Educação, São Paulo, v. 24, n. 1, jan. 1998. Disponível em: < http://www.scielo.br/scielo.php?script=sci_arttext\&pid=S0102$25551998000100004 \& \operatorname{lng}=$ en\&nrm $=$ iso $>$. Acesso em: 25/4/12. 
FRANKENBERG, E.; SIEGEL-HAWLEY, G; WANG, J. Choice without equity: Charter school segregation. Educational Policy Analysis Archives, Phoenix, v. 19, n. 1, jan. 2011. Disponível em < http://epaa. asu.edu/ojs/article/view/779>. Acesso em: 26/04/2012.

FRIEDMAN, M. Capitalismo e liberdade. São Paulo: Arte Nova, 1977.

GOMES, C. et al. Reforço escolar: gastos e desigualdades sociais. Revista Brasileira de Estudos Pedagógicos, Brasília, v. 91, n. 227, p. 55-74, jan./abr. 2010.

JESUS. W. O "problema nacional": a história de uma emenda que transformou o financiamento da educação no Brasil. Revista Brasileira de Estudos Pedagógicos, Brasília, v. 88, n. 220, p. 421-444, set./dez. 2007.

LEVIN, H. School finance. In: CARNOY, M. (Org.). International encyclopedia of economics of education. 2. ed. New York: Pergamon Press/Elsevier Science, 1995. p. 412-419.

A Comprehensive framework for evaluating educational vouchers. Educational Evaluation and Policy Analysis, Thousand Oaks, CA, v. 24, n. 3, p. 159-174, Fall 2002.

MELCHIOR, J. C. O financiamento da educação no Brasil. São Paulo: EPU, 1987.

MERCHEDE, A. Custos da educação infantil: o caso de duas instituições do Distrito Federal. Revista Brasileira de Estudos Pedagógicos, Brasília, v. 79, n. 192, p. 30-47, maio/ago. 1998.

PARENTE, C. D. Assistência financeira do FNDE/MEC a programas e projetos educacionais: formato e implicações. Revista Brasileira de Estudos Pedagógicos, Brasília, v. 87, n. 215, p. 19-28, jan./abr. 2006.

PINTO, J. M. et. al. Relatório do Grupo de Trabalho sobre Financiamento da Educação. Revista Brasileira de Estudos Pedagógicos, Brasília, v. 82, n. 200/201/202, p. 117-136, jan./dez. 2001.

PSACHAROPOULOS, G. et al. El financiamiento de la educación en los países en desarollo: opciones de política. Washington, D.C.: Banco Mundial, 1987.

SCHULTZ. T. The economic value of education. New York: Columbia University Press, 1963.

SENA, P. A União e a aplicação dos recursos vinculados à manutenção e ao desenvolvimento do ensino. Revista Brasileira de Estudos

Pedagógicos, Brasília, v. 83, n. 203/204/205, p. 7-22, jan./dez. 2002. 
VELLOSO, J. A Emenda Calmon e os recursos da União. Cadernos de Pesquisa, São Paulo, n. 74, p. 20-39, ago. 1990.

. Income distribution and education. In: CARNOY, M. (Org.). International encyclopedia of economics of education. 2. ed. New York: Pergamon Press/Elsevier Science, 1995. p. 230-235.

. Universidade na América Latina: rumos do financiamento. Cadernos de Pesquisa, São Paulo, n. 110, p. 39-66, jul. 2000.

. Pesquisas no País sobre o financiamento da educação: onde estamos? In: WHITTMAN, L.; GRACINDO, R. V. (Orgs.). O estado da arte em política e gestão da educação no Brasil: 1991 a 1997. Brasília: Anpae; Campinas: Autores Associados, 2001. p. 109-132.

VERGER, A.; BONAL, X. La estrategia educativa 2020 o las limitaciones del Banco Mundial para promover el "aprendizage para todos". Educação \& Sociedade, Campinas, v. 32, n. 117, p. 911-932, out./dez. 2011.

Jacques Velloso, doutor em Educação pela Stanford University, é professor emérito da Universidade de Brasília (UnB) e pesquisador colaborador da Faculdade de Educação dessa instituição.

jacques.velloso@terra.com.br 